\title{
Bilateral Gastrocnemius Muscle Rupture in a Bovine
}

\section{Ana Paula Mori', Claiton Ismael Schwertz ${ }^{2}$, Luan Cleber Henker ${ }^{3}$, Fernanda Agustini Stedille ${ }^{3}$, Ricardo Christ ${ }^{3}$, Marina Paula Lorenzett ${ }^{2}$, Fabrisio Broll ${ }^{4} \&$ Ricardo Evandro Mendes ${ }^{3}$}

\begin{abstract}
Background: Locomotor system diseases are quite common in the field practice in dairy cattle and represent an important cause of economics losses. The rupture of the gastrocnemius muscle has been reported in humans, cattle, horses, camels and llamas. It can be complete or partial. The rupture of muscle as well as sacral fractures are infrequent, and consequently not commonly reported in veterinary medicine. The aim of this work was to report a case of bilateral gastrocnemius rupture in a dairy cow related to a sacral (S2) fracture.

Case: A 3-year-old Holstein cow with lameness and urinary incontinence was presented for clinical examination. After three days, clinical signs progressed to sternal recumbency and difficulty to keep normal posture. While standing, the cow's tarsal joint showed a $90^{\circ}$ degree angle with tibia, in a manner that the metatarsal bones were completely leant on the ground. Also, a marked enlargement in both gastrocnemius area were observed. The animal was in good body condition and alert, although unable to maintain both hind limbs extended straight, and was not able to raise the tarsal joint off the ground. Physiological parameters presented normal values. Due to the poor prognosis, euthanasia and necropsy were conducted. At necropsy, it was observed that in both hind limbs the gastrocnemius muscle was ruptured, presenting severe diffuse dark red color, severe enlargement, and moderate diffuse edema and emphysema. The rupture was complete and observed at both muscular insertions in the calcaneus bone. Besides the muscular alterations, the animal had a 2 centimeters fracture on the second sacral vertebra, associated with focally extensive hemorrhage in the spinal canal and meninges. Histologically the main findings were degeneration and severe diffuse necrosis of muscle fibers associated with severe hemorrhage, and mild infiltrate of neutrophils

Discussion: Fractures in cattle may occur due to multiples causes, however farm management and facilities play an important role in the incidence of these disorders. Slippery floors along with groups composed of animals of different sizes and ages are a major cause of injury in this species. The consequence of a vertebral fracture vary greatly according to the location and extent of the injury, the degree of spinal cord compression and which spinal anatomical structures are involved. Besides the direct damage caused by the fractures in the bone's stability, changes can also occur in related structures, such as muscles and tendons, which are extremely important for the animal to maintain its normal stance and move adequately. One example is the trauma of gastrocnemius muscle that is found sporadically due to struggling. In this case it is conjectured that the pain and the spinal cord compression at the fracture's location, lead to difficulty for the animal to rise, culminating with the ruptured muscles by overexertion. The characteristic position adopted by the animal was useful to establish the diagnosis, although necropsy was necessary to confirm it. Once the occurrence of this condition is infrequent, this report becomes important to aid veterinarians in order to differentiate it from other diseases of the musculoskeletal and nervous systems, including toxic conditions as Senna sp. and ionophore poisoning, besides nutritional myopathies such as vitamin E and selenium deficiency. Coxofemoral luxation and infectious diseases such as rabies and botulism should also be considered.
\end{abstract}

Keywords: vertebral fracture, recumbency, myopathy. 


\section{INTRODUCTION}

Changes in muscular, osteoarticular and nervous components may affect the animal's ability to maintain its normal stance, being diseases of the locomotor system among the main causes of culling in dairy cows [10]. Locomotor system diseases are quite common in the field practice in dairy cattle, and frequently are associated with hipocalcemia, hoof pathologies and dystocia [4].

The rupture of the gastrocnemius muscle has been reported in humans, cattle, horses, camels and llamas, although is infrequent $[1,12]$. In most cases the rupture is complete, however there are cases of partial tearing [6]. The muscle-tendon junction, the muscular origin, and the insertion are the most common locations of rupture of the gastrocnemius muscle in cattle [1]. It can occur shortly after an injury or due to weakening of the muscle and tendon in a manner that a small amount of effort is sufficient to cause the rupture [13]. In cases of complete rupture, the animal is not able to bear weight on the affected limb and can adopt a position with the metatarsal bones resting on the ground. Animals with hypocalcemia and handled in places with slippery floor are particularly prone [6]. The aim of this work was to report a case of bilateral gastrocnemius rupture in a dairy cow related to a sacral $(\mathrm{S} 2)$ fracture.

\section{CASE}

This study aims to report a case of complete bilateral rupture of the gastrocnemius muscle in cattle. A 3-year-old, 5-month-pregnant Holstein cow was euthanized due to the poor prognosis after clinical evaluation. Clinical history was obtained from the field veterinarian and the farm owner.

The necropsy was conducted by the Veterinary Pathology Laboratory of the Instituto Federal Catarinense-Campus Concórdia. Fragments of the gastrocnemius muscle, sciatic nerve, central nervous system, bones and organs of the abdominal and thoracic cavities were collected, fixed in $10 \%$ buffered formalin, wax embedded, and cut in sections ranging from 3 to $5 \mu \mathrm{m}$. The slides were stained with hematoxylin and eosin technique (H\&E) for histopathological evaluation.

The animal was kept in a semi-intensive farming system and fed with Tifton pasture (Cynodon sp.), corn silage, concentrate, and mineral premix for lactating dairy cows. According to the farmer, the clinical signs began with sudden walking difficulty, accompanied by urinary incontinence. On the third day the cow adopted sternal recumbency, showing inability to keep normal stance. After repeated attempts to rise, the animal kept its metatarsal bones, and tarsal joint on the ground forming a right angle $\left(90^{\circ}\right.$ degree angle) with the tibia and fibula (Figure 1). A veterinarian established symptomatic treatment, but after three days in decubitus, and due to the poor prognosis, euthanasia and necropsy were performed.

At the clinical examination the animal was in good body condition and alert, although unable to keep adequate stance. The cow could not maintain both hind limbs extended straight, and was not able to raise the tarsal joint off the ground; pelvic limbs did not present withdrawal reflex, suggesting loss of superficial pain reflexes. Tail paralysis and urinary incontinence were also noted, as well as decubitus ulcers on the tarsal joint. Physiological parameters presented normal values.

At necropsy, both gastrocnemius muscle were severely enlarged, showing mild crepitation and moderate edema. At the cut surface, muscular groups showed dark-red to blackish color, with areas of emphysema, and draining moderate amount of serosanguineous fluid. In some areas there was a moderate amount of fibrin distributed on the musculature (Figure 2). Popliteal lymph nodes were severally enlarged. A complete rupture was observed at both insertions of gastrocnemius muscle in the calcaneus bone. Additionally, the sacral vertebrae gross evaluation revealed a $2 \mathrm{~cm}$ fracture located in the body of the S2 (Figure 3), associated with focally extensive hemorrhage in the leptomeninges.

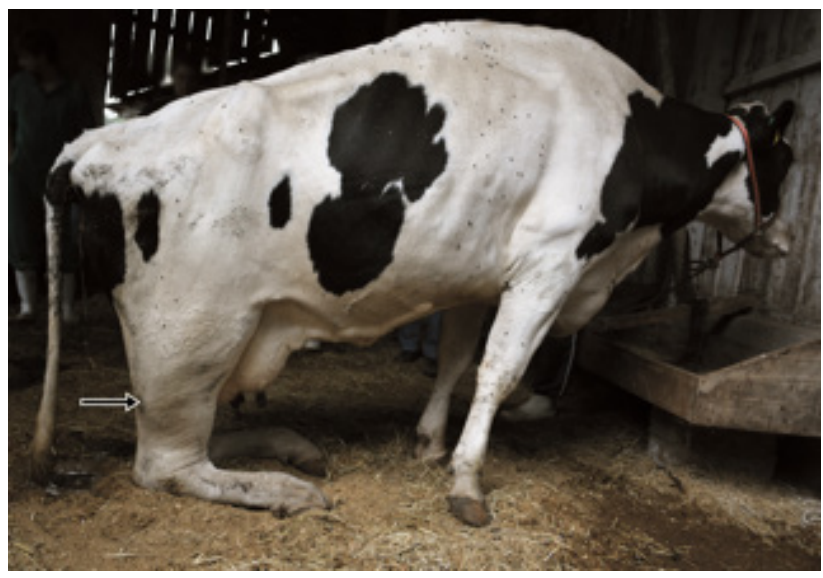

Figure 1. Holstein cow with complete bilateral gastrocnemius rupture. In an attempt to keep normal stance the animal presents the tarsal joints flexed, and metatarsal bones disposed in parallel to the ground. Moderate enlargement of muscles located proximally to the tarsal joints (arrow). Tail paralysis and urinary incontinence were observed. 


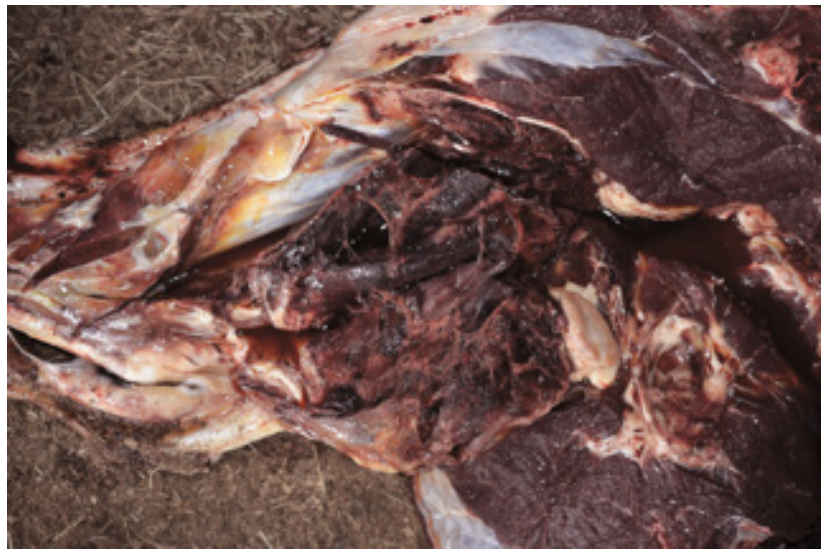

Figure 2. Right hindlimb. The muscles located proximally to the tarsal joint present dark-red to blackish color (extensive hemorrhage and muscular necrosis), serous fluid (edema), and moderate amount of fibrin deposition.

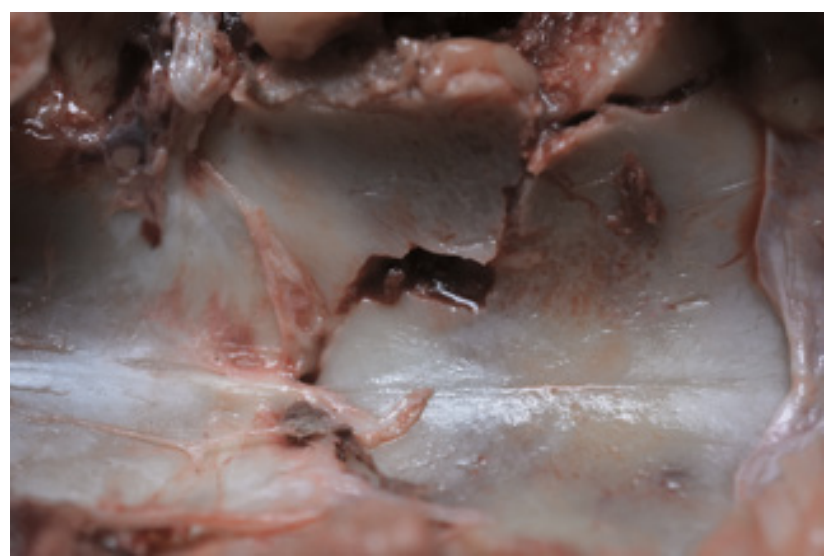

Figure 3. Vertebral column. A fracture measuring approximately $2 \mathrm{~cm}$ is observed in the second sacral vertebra (S2).

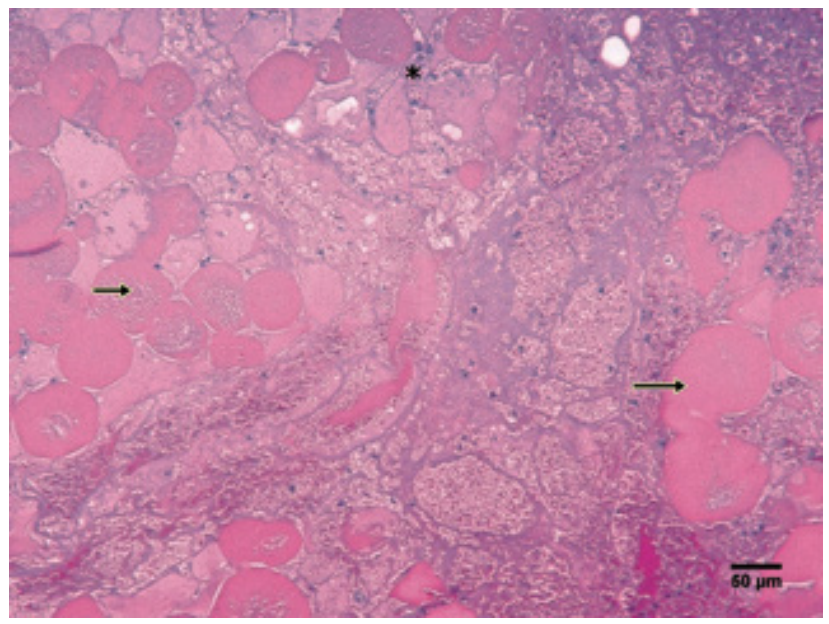

Figure 4. Gastrocnemius muscle (H\&E). Histological evaluation reveals severe diffuse necrosis of muscle fibers (arrows), associated with eosinophilic amorphous material between myocytes (proteinaceous edema and fibrin), and discrete inflammatory infiltrate of neutrophils (asterisk) [160x]. The necrotic myofibers are swollen, deeply eosinophilic, show rounded contour, and lacked cross striations (hyalinization) indicating an initial stage of necrosis.
Histological evaluation of the gastrocnemius muscles revealed severe multifocal degeneration and necrosis of muscle fibers associated with hemorrhage, edema, fibrin deposition and discrete inflammatory infiltrate of neutrophils. The myofibers were swollen, deeply eosinophilic, presented rounded contour, and lacked cross striations (hyalinization) indicating an initial stage of necrosis (Figure 4).

\section{DISCUSSION}

Fractures in cattle may occur due to multiple causes, however farm management and facilities play an important role in the incidence of these disorders. Slippery floors and several animals of different sizes or ages are a major cause of injury in this species [9]. According to a retrospective study conducted by Borges et al. [3], vertebral fractures are observed more frequently in cattle followed by horses, sheep, goats and pigs. In this report, the vertebral fracture should have a traumatic origin, but was not possible to establish the definitive cause. The farm owner reported that a cow in estrus mounted the injured animal previously to the development of clinical signs. However, in cases where the vertebral fracture is associated with natural mating, usually the vertebral column segment affected is the lumbar and not sacral [3]. It is also possible that the trauma had an iatrogenic origin, being caused by farm workers while handling the herd. Our research group has seen this pattern of fracture due to lightning, both in swine and cattle, mainly in sacral vertebrae and femur. Even though normally more than one animal is affected.

Progressive posterior paresis is described as a clinical sign of sacral damage [2]. The same clinical sign was observed in this report, probably associated with the sacral fracture. The consequences of a vertebral fracture vary greatly according to the location and extent of the injury, the degree of spinal cord compression and which spinal anatomical structures are involved [11]. Besides the direct damage caused by the fractures in the bone's stability, changes can also occur in related structures, such as muscles and tendons, which are extremely important for the animal to maintain its normal stance and move adequately.

Trauma of the gastrocnemius muscle is found sporadically due to struggling, when a cow with hipocalcemia attempts to stand [2]. In this case, it is conjectured that the vertebral fracture triggered the rupture of the gastrocnemius muscles. At the location 
of the fracture, there was displacement of bone fragments inside of the spinal canal and hemorrhage, thus causing compression of the spinal cord and emerging spinal nerves. The compromised nervous function, the absence of bone stability and the pain prevented the animal to move properly, what started the clinical signs.

Probably at some point, the animal spent a great muscular effort to rise, resulting in the rupture of the gastrocnemius muscles. The clinical signs reported corroborate this conclusion, since according to the farmer, the animal presented a period of three days with walking difficulty, accompanied by urinary incontinence, which we believed were due to the sacral lesion. Latter, on the third day the cow adopted sternal recumbency, showing inability to keep normal stance, what we believe was due to the muscular rupture. Animals with gastrocnemius trauma can present two clinical signs: a dropped hock and swelling of the muscle, most common is cases of unilateral lesion, as well as, incapacity to stand and bear weight on the plantar surface of the hock, normally found in cases of complete bilateral rupture [2].

Mineral deficiencies also facilitate muscular ruptures. Calcium is a mineral crucial to maintain muscle tone, and generalized muscular weakness and atony are effects of hypocalcaemia [1]. In this case, seric levels of calcium were not measured, however, it is unlikely that the animal presented hypocalcemia, since the cow was on its eighth lactation month, and this clinical condition occurs most commonly in the peripartum period. Furthermore, the diet fed to the herd was formulated by an animal nutritionist. According to Altug et al. [1], low levels of calcium are an important predisposing factor in the development of gastrocnemius rupture. These authors report the case in which of a cow developed the disease two months after giving birth to twins. In that case, the maintenance of two calves along with the high lactation demands generated maximum calcium mobilization.

The differential diagnosis should include diseases that cause muscle necrosis and consequently locomotor disorders, such as toxic conditions as Senna sp. and ionophore poisoning [8], and nutritional myopathies such as vitamin E and selenium deficiency [7]. These diseases cause lesions in multiple muscular groups, and are not limited to the gastrocnemius muscle, as observed in this case. Infectious diseases such as rabies [8] and botulism [5] should also be considered, although these disorders have a distinct clinical presentation. Coxofemoral luxation, which can also cause recumbency, can be diagnosed easily by examination of the joint.

In the case reported here, the diagnosis of bilateral rupture of the gastrocnemius muscle was established through the association of clinical signs and necropsy findings. It is highlighted that the position adopted by the animal after the muscular rupture is characteristic of this disorder. It is believed that the muscular tear occurred after spinal injury which led the animal to overexertion in order to stand up. Although the occurrence of this condition is infrequent, this report becomes important to aid veterinarians in order to differentiate it from other diseases of the musculoskeletal and nervous systems.

Acknowledgments. Authors are grateful to Simon Hugh Wheeler for proofreading. Work supported by grants from the Instituto Federal Catarinense (IFC), 455/2014 PROEX/IFC and from the National Council for Scientific and Technological Development (CNPq), No 468602/2014-3.

Declaration of interest. The authors report no conflicts of interest. The authors alone are responsible for the content and writing of the paper.

\section{REFERENCES}

1 Altuğ N., Özkan C., Yüksek N., Karasu A., Keleş I., Ağaoğlu Z.T. \& İlhan F. 2007. Rupture of the gastrocnemius muscle in a cow two months after twin birth. Bulletin of the Veterinary Institute in Pulawy. 51: 615-619.

2 Blowey R. \& Weaver A. D. 2012. Locomotor disorders. In: Blowey R. \& Weaver A.D. (Eds). Color Atlas of Diseases and Disorders of Cattle. 3rd edn. London: Mosby, pp.137-138.

3 Borges A.S., Silva D.P.G., Gonçalves R.C., Chiacchio S.B., Amorim R.M., Kuchembuck M.R.G., Vulcano L.C., Bandarra E.P. \& Lopes R.S. 2003. Fraturas vertebrais em grandes animais: estudo retrospectivo de 39 casos (19872002). Arquivo Brasileiro de Medicina Veterinária e Zootecnia. 55(2): 127-132.

4 Craig L.E., Dittmer K.E \& Thompson K.G. 2016. Bones and joints. In: Maxie M.G. (Ed). Jubb, Kennedy and Palmer's Pathology of Domestic Animals. v.1. 6th edn. St. Louis: Elsevier, pp.16-163.

5 Dutra I.S, Döbereiner J., Rosa I.V., Souza L.A.A. \& Nonato M. 2001. Surtos de botulismo em bovinos no Brasil 
associados à ingestão de água contaminada. Pesquisa Veterinária Brasileira. 21(2): 43-48.

6 Guard C. 2008. Musculoskeletal Disorders. In: Divers T.J. \& Peek S.F. (Eds). Rebhun's Diseases of dairy cattle. 2nd edn. St. Louis: Saunders, pp.467-503.

7 Nogueira V.A., França T.N. \& Peixoto P.V. 2009. Intoxicação por antibióticos ionóforos em animais. Pesquisa Veterinária Brasileira. 29(3): 191-197.

8 Sanches A.W.D., Langohr I.M., Stigger A.L. \& Barros C.S.L. 2000. Doenças do sistema nervoso central em bovinos no Sul do Brasil. Pesquisa Veterinária Brasileira. 20(3): 113-118.

9 Sherman D.M. 1987. Localized Diseases of the Bovine Brain and Spinal Cord. Veterinary Clinics of North America: Food Animal Practice. 3(1): 179-191.

10 Silva L.A.F., Coelho K.O., Machado P.F., Silva M.A.M., Moura M.I., Barbosa V.T., Barbosa M.M. \& Goulart D.S. 2008. Causas de descarte de vacas da raça holandesa confinadas em uma população de 2.083 bovinos (2000-2003). Ciência Animal Brasileira. 9(2): 383-389.

11 Smith M.O. \& George L.W. 2009. Diseases of the Nervous System. In: Smith B.P. (Ed). Large animal internal medicine. 4th edn. St. Louis: Mosby, pp.972-1111.

12 Tyler J.W., Middleton J.R., Barbee D.D. \& Parish S.M. 1998. Conservative management of a ruptured gastrocnemius muscle in a male llama. The Canadian Veterinary Journal. 39(11): 712-713.

13 Wheat J.D. \& Asbury A.C. 1958. Rupture of the gastrocnemius mucle in the cow - A case report. Journal of the American Veterinary Medical Association. 132: 331-332. 